\title{
Medio-Frontal and Anterior Temporal abnormalities in children with attention deficit hyperactivity disorder (ADHD) during an acoustic antisaccade task as revealed by electro-cortical source reconstruction
}

\author{
Johanna Goepel*, Johanna Kissler, Brigitte Rockstroh, Isabella Paul-Jordanov
}

\begin{abstract}
Background: Attention Deficit Hyperactivity Disorder (ADHD) is one of the most prevalent disorders in children and adolescence. Impulsivity is one of three core symptoms and likely associated with inhibition difficulties. To date the neural correlate of the antisaccade task, a test of response inhibition, has not been studied in children with (or without) ADHD.

Methods: Antisaccade responses to visual and acoustic cues were examined in nine unmedicated boys with ADHD (mean age $122.44 \pm 20.81$ months) and 14 healthy control children (mean age $115.64 \pm 22.87$ months, three girls) while an electroencephalogram (EEG) was recorded. Brain activity before saccade onset was reconstructed using a 23-source-montage.

Results: When cues were acoustic, children with ADHD had a higher source activity than control children in Medio-Frontal Cortex (MFC) between -230 and -120 ms and in the left-hemispheric Temporal Anterior Cortex (TAC) between -112 and 0 ms before saccade onset, despite both groups performing similarly behaviourally (antisaccades errors and saccade latency). When visual cues were used EEG-activity preceding antisaccades did not differ between groups.

Conclusion: Children with ADHD exhibit altered functioning of the TAC and MFC during an antisaccade task elicited by acoustic cues. Children with ADHD need more source activation to reach the same behavioural level as control children.
\end{abstract}

\section{Background}

Children with ADHD have difficulties with cognitive control, working memory and response inhibition [1]. Response inhibition consists of two processes: (i) the capacity to suppress a prepotent response before or after its initiation, and (ii) the goal-directed behaviour from the interference of competing processes [2]. Antisaccades are one way to examine inhibition, as antisaccade tasks require the suppression of the automatic response to look towards a peripheral cue and to generate a saccade in the opposition direction instead [3].

\footnotetext{
* Correspondence: Johanna.Goepel@uni-konstanz.de

Department of Psychology, University of Konstanz, Konstanz, Germany
}

Error rates during antisaccade tasks reflect the ability to inhibit a response, while saccadic reaction times (SRT) during correct trials reflect the duration of the underlying cognitive and motor processes. There is a growing body of literature on eye movement experiments comparing children with ADHD with control subjects [4]. Despite some inconsistencies, the general finding is that subjects with ADHD have an elevated number of direction errors during antisaccade tasks [5-13]. However, until now, no study has examined brain function during antisaccade tasks in ADHD, although this might lead to important new insight into the cortical mechanisms of behavioural inhibition and its dysfunction in ADHD. 
Inhibition difficulties are not only relevant in the visual domain, where they have mostly been studied. Humans also redirect their gaze to locate the origin of a suddenly appearing noise, a tendency, which is already present in babies [14]. Still, until now, there is no study, which investigates pro- or antisaccades elicited by acoustic cues in children. Accordingly, it is unclear, which neuronal network underlies antisaccades following acoustic cues. There is a particular interest in analysing inhibition deficits following auditory cues in children with ADHD as a high number of children with ADHD have difficulties with acoustic tasks [15-17].

Electrophysiological and functional brain imaging studies have given insight into which cerebral areas are active during visual saccadic tasks. The Frontal Eye Fields (FEF), the Supplementary Eye Fields (SEF) and the Parietal Eye Fields (PEF) in the Posterior Parietal Cortex (PPC) are active when saccades are initiated. The Dorsolateral Prefrontal Cortex (DLPFC) and the Anterior Cingulate Cortex (ACC) with the Cingulate Eye Field are associated with "higher level", volitional and cognitive aspects of saccade control, specifically during antisaccades [18-26]. DLPFC shows activity during antisaccades that is not present during prosaccades [27]. Its activity seems to provide an inhibitory signal that precedes correct antisaccade performance [28-30]. Directional errors are therefore generally linked to frontal dysfunctions. The ACC is involved in the executive control of attention and plays an important role in visual antisaccade performance [24,31-33]. Given that children with ADHD have difficulties with response inhibition and make more antisaccade errors than children without ADHD, one might assume that activity of frontal structures involved in the generation of antisaccades is altered. Disturbed functioning of Prefrontal Cortex, ACC, and striatum are also thought to underlie other executive function deficits in ADHD [34]. This is in line with the aetiological theory that ADHD results from structural and functional changes in a fronto-subcortical network [34-36].

The first aim of the present study was to investigate how children with and without ADHD differ in brain activation during an antisaccade task. The second aim was to investigate, whether children with ADHD have comparable inhibition difficulties when cues are visual and acoustic.

\section{Methods \\ Participants}

Sixteen children with ADHD and sixteen children without ADHD were investigated. Children with ADHD were recruited at two child psychiatric outpatient clinics, diagnoses being made by the head psychiatrist and his/her team of psychologists based on questionnaires, anamnestic biographical interviews and psychometric tests. Control children were recruited at a local school. However, data of seven children with ADHD and data of two control children had to be discarded due to insufficient data quality (too many movement artefacts). Data of nine children with ADHD (mean age $122.44 \pm 20.81$ months, boys only) and 14 healthy control children (mean age 115.64 \pm 22.87 months, three girls) were further analysed. All but one child with ADHD were diagnosed with ADHD combined type; the remaining child was diagnosed with ADHD primarily inattentive type. All children were investigated off medication. Three children with ADHD who were prescribed with methylphenidate refrained from taking it at least 24 hours before the experiment in concordance with their respective psychiatrist and their parents. All children with ADHD had at least one comorbid disorder (mostly specific developmental disorder of motor function) and $44 \%$ had at least two comorbid disorders (mostly specific developmental disorders of scholastic skills). Control children did not have any clinically relevant diagnoses or took any medication as reported by the parents.

\section{Procedure}

Children and parents were shown the laboratory equipment and the task was explained to them. They then signed informed consent forms (according to the Helsinki declaration [37]). Parents were asked to fill in an ADHD symptom checklist [38], an auditory processing disorder (APD) checklist [39] and a routine questionnaire while children completed the Edinburgh-Handedness-Inventory [40]. To ensure within-normal hearing levels, children's hearing thresholds were determined for frequencies 500,1000, 2000 and $4000 \mathrm{~Hz}$ in an acoustically shielded room. Children were then shown a computerised, animated explanation of the task, which included examples and four training trials. To ensure that all children were motivated and perceived themselves as successful, children were told that they would be able to collect four "cartoon dogs" on the computer screen if they performed well (the dogs always appeared after fixed intervals) which would then allow the children to pick a small gift from a "treasure chest" after the experiment. Children were additionally compensated with 20 Euros at the end of the experimental session.

For the EEG experiment, children were comfortably seated in a chair, their heads resting on a chin rest 500 $\mathrm{mm}$ away from the computer monitor. Headphones were put on and the $30 \mathrm{~min}$ - experiment was started after impedance measurement. After the EEG experiment intelligence was assessed by the Coloured Progressive Matrices (CPM) [41].

\section{Task}

Participants were instructed to generate saccades in response to visual or acoustic cues. The nature of the 
required saccade depended on the instruction. Saccades could either be directed towards the cue (prosaccade) or away from the cue (antisaccade). Visual cues, consisting of yellow dots that filled one of four empty circles, could appear "near" $\left(6^{\circ}\right)$ or "far" $\left(12^{\circ}\right)$ and left or right of the fixation cross for $1000 \mathrm{~ms}$. Acoustic cues were 1000 $\mathrm{Hz}$ sine tones presented for $1000 \mathrm{~ms}$ that were perceived either "far" left/right $\left(90^{\circ}\right)$ or "near" left/right $\left(45^{\circ}\right.$, see the description below). Children were explained that in response to "near" acoustic cues they should generate saccades towards the $6^{\circ}$ circle, and upon "far" to make saccades towards the $12^{\circ}$ circle. Cues could either appear $200 \mathrm{~ms}$ after extinction of the fixation cross (gap) or with a $200 \mathrm{~ms}$ overlap with the fixation cross. Random combinations of the following withingroup factors were presented throughout the experiment: cue modality (visual vs. acoustic), direction (right vs. left), type (anti- vs. prosaccade), distance (near $\left(6^{\circ}\right.$ visual, $45^{\circ}$ acoustic) vs. far ( $12^{\circ}$ visual, $90^{\circ}$ acoustic) ) and delay (gap vs. overlap). Nine runs of each combination resulted in a total of 288 trials. This random design was chosen to avoid ceiling effects and enable better group differentiation.

After trial 96, 129, 259 and 288 children were shown a motivation picture with $1,2,3$ and 4 dogs, respectively. A pause-signal appeared after 144 trials indicating that children could take a short break. The length of the break was determined by the children.
Each trial began with a $1000 \mathrm{~ms}$ instruction slide depicting the nature of the required saccade by a prominent symbol the meaning of which had been explained to the children beforehand (see procedure above). Each trial lasted $6500 \mathrm{~ms}$ (see Figure 1 for a schematic overview).

\section{Equipment and Recordings}

Cues were presented with the software Presentation (Neurobehavioral Systems, Inc.). Visual cues were generated within Presentation. Sine tones were generated with Adobe Audition $2.0^{\circledR}$. The effect of sound lateralisation was created by intensity and phase differences between the left and right channel. The impression of a $90^{\circ}$ lateralisation to either direction was created by attenuating the contra-lateral channel by $3.62 \mathrm{~dB}$ and shifting its onset by $6.5 \mu \mathrm{s}$. The impression of a $45^{\circ}$ lateralisation was created by attenuating the contralateral channel by $2.8 \mathrm{~dB}$ and delaying its onset by $1 \mu \mathrm{s}$.

Stimuli were presented with a PC Dell precision 390 with Intel ${ }^{\circledR}$ Core ${ }^{\mathrm{TM}} 2 \mathrm{CPU} 2.13 \mathrm{~Hz}$-processor with $2 \mathrm{~GB}$ Ram operating system on a monitor with $365 \times 270$ $\mathrm{mm}$ resolution (Samtron $96 \mathrm{BDF}$ ) and via stereo headphones (Sennheiser HD 280 pro $(64 \Omega)$ ).

Electrical brain activity was measured using EEG. Recording was done with a 257 channel system from EGI Electrical Geodesics Inc. using NetStaion ${ }^{\mathrm{TM} 12}$ on a Mac OSX with $1,25 \mathrm{GHz}$ PowerPC G4 processor and 1 GB DDR SD RQM. Sample rate was $250 \mathrm{~Hz}$ and an

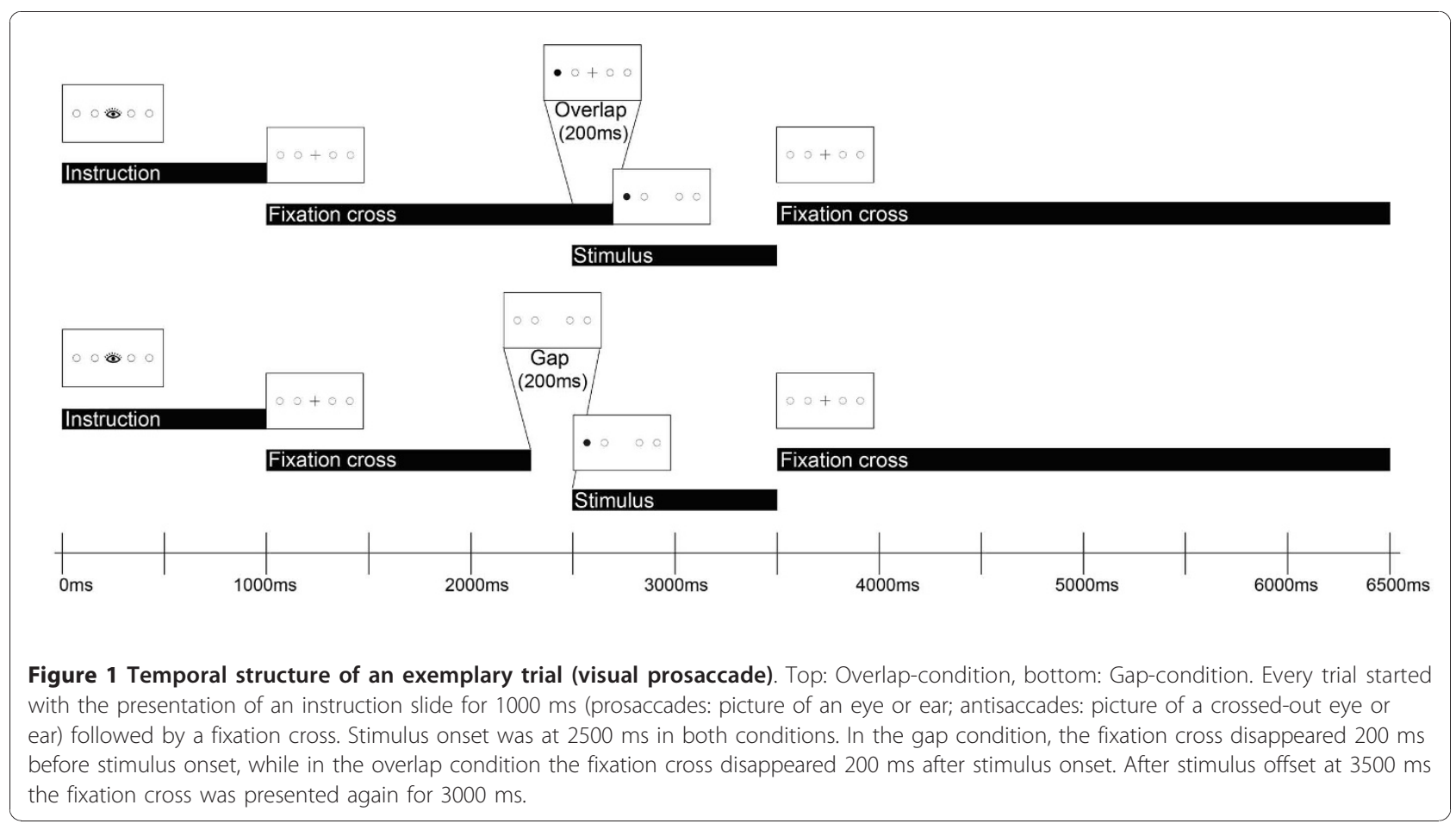


online filter of $100 \mathrm{~Hz}$ lowpass and $0.1 \mathrm{~Hz}$ highpass were applied.

\section{Data analysis}

Data were analysed with BESA software (Brain Electrical Analysis, version 5.2.4.52, MEGIS Software GmbH, Graefelfing, Germany). Vertical and horizontal eye movements artefacts (blinks and saccades) were systematically removed using an algorithm implemented in BESA $[42,43]$. For each condition, data were segmented into epochs from $500 \mathrm{~ms}$ pre to $2000 \mathrm{~ms}$ post stimulus (notch filter at $50 \mathrm{~Hz}$ ). For the identification of saccades, data were filtered digitally from $0.01-8 \mathrm{~Hz}(6 \mathrm{~dB} /$ octave forward and $12 \mathrm{~dB} /$ octave zerophase). The percentage of correct saccades was determined and saccade latency was measured to the nearest sampling point. Saccades with latencies $<80 \mathrm{~ms}$ were excluded, as they can be classified as anticipations rather than responses [44]. Next, unfiltered response-locked averages of antisaccades (merged across direction, distance and delay to gain higher statistical power and more averages for source reconstruction) were generated i.e. epochs $(500 \mathrm{~ms}$ pre and $500 \mathrm{~ms}$ post response) were exported, which were centred at saccade onset. Source analysis was carried out with a 23 -sourcemodel (generated on the basis of talairach coordinates of structures known to be involved in saccade generation), data being filtered digitally from $0.1-30 \mathrm{~Hz}(6 \mathrm{~dB}$ /octave forward and $24 \mathrm{~dB} /$ octave zerophase). The source montage was generated to cover activity of structures relevant for the processing and production of saccades (FEF, DLPFC, PPC - left and right, SEF, Frontal Midline (FM) and Medio-Frontal Cortex (MFC)). Further, sources were placed that covered activity of structures relevant for the processing of acoustic and visual stimuli (Supplemental Temporal Cortex (STC), Temporal Parietal Cortex (TPC), Temporal Anterior Cortex (TAC) and Occipital Cortex (OCC) - left and right). Additional sources of no interest (Cerebellum (CB) - left and right) were placed to increase the sensitivity of the sources of interest. The sensitivity of a source describes its ability to pick up the activity generated by the brain volume of interest. Source sensitivity is dependent on the position of the source in the brain model, the number of sources in the montage, as well as the distance between the sources. The sensitivity of relevant sources was carefully tested with sensitivity maps in BESA (see Figure 2 for the sensitivity map). The output of a source montage is each individual source's activity over time. Source positions in space are fixed.

\section{Statistical analysis}

Only antisaccades were analysed, as the leading question of the present article concerned response inhibition. Saccadic reaction times (SRTs) and the percentage of correctly generated antisaccades (merged across direction, distance and delay) were compared between groups using Statistica (StatSoft, Inc., 2003). T-tests or MannWhitney-U tests were computed after testing for normal distribution of the dependent variables using ShapiroWilks-W-test. Scores of questionnaire data were analysed accordingly. In order to objectively identify time-windows, throughout which the experimental groups differed in activity of one or more sources, non-parametric

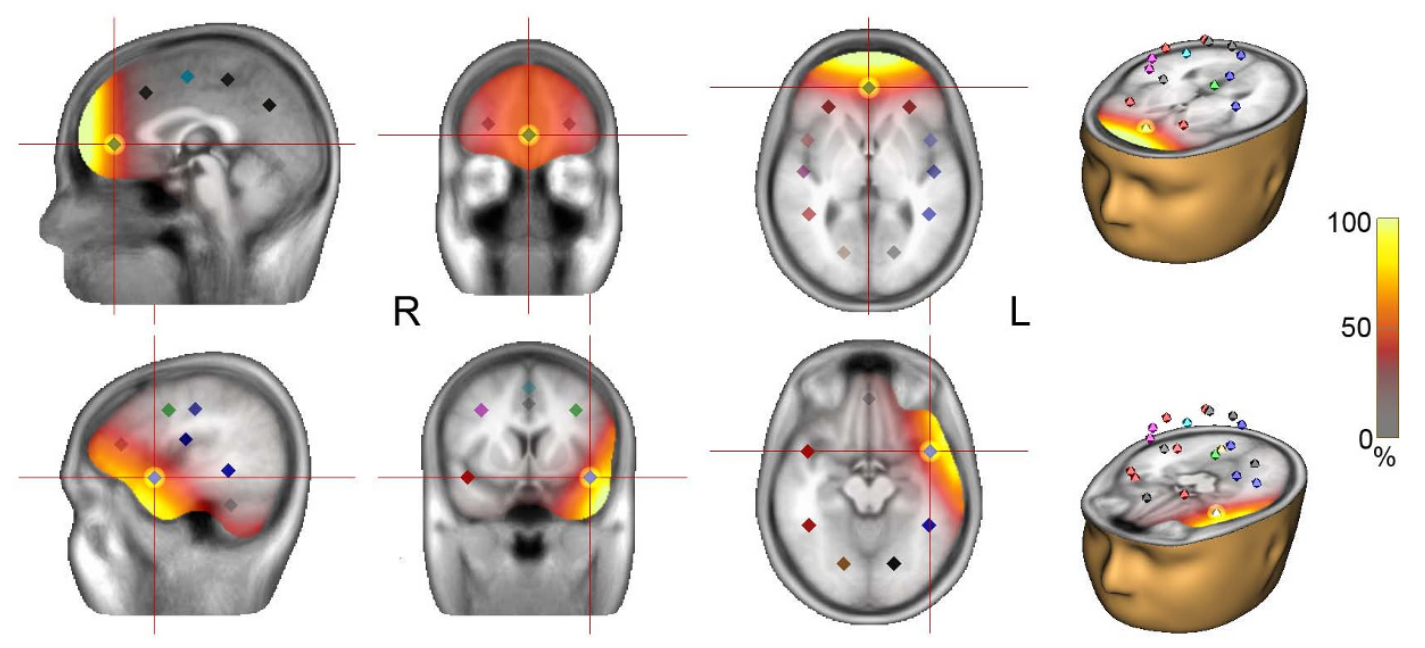

Figure 2 Sensitivity map of the MFC (top) and the TAC left (bottom). Location and sensitivity of the MFC and TAC source in sagittal, transversal and horizontal view. 
cluster-based analysis of EEG source data was performed using FieldTrip, an open-source signal processing toolbox for Matlab (Donders Institute for Brain, Cognition and Behaviour, Radboud University Nijmegen, The Netherlands. http://www.ru.nl/neuroimaging/fieldtrip). Groups were compared for each sampling point and each source via independent $t$-tests. In order to prevent chance-findings, data were re-shuffled 1000 times using a cluster-based Monte-Carlo randomization.

This method effectively controls for multiple comparisons [45]. Clusters (here: clusters of sampling points) were defined as significant when the probability of observing larger effects in the shuffled data was below $5 \%$. As response inhibition takes place before the onset of the saccade and in accord with already existing findings $[29,30]$, data analysis was carried out for the timewindows $-230 \mathrm{~ms}$ until $-120 \mathrm{~ms}$ before response and $-120 \mathrm{~ms}$ until $20 \mathrm{~ms}$ after response.

\section{Results}

\section{Sample characteristics}

Groups did not differ in age $(t(21)=0.689, p=.499)$ or gender distribution $\left(\chi^{2}(1)=2.22, p=.135\right)$. Children with and without ADHD had comparable intelligence scores as measured by the CPM (ADHD: $71.00 \pm 29.97$ percentile rank, Control: $66.15 \pm 29.84$ percentile rank; $t(19)=0.361, p=.722)$. Children with and without ADHD had hearing sensitivities of $20 \mathrm{~dB}$ or better in each ear for all measured frequencies [46]. Groups did not differ from each other (see table 1).

Children with ADHD had higher values than control children for both subscales of the ADHD questionnaire (see table 2). Groups also differed on the subscales Speech Perception and Auditory Memory of the APD questionnaire (see table 2).

\section{Saccadic reaction and latencies}

Groups did not differ regarding correct antisaccade reactions in the visual condition (ADHD $50.52 \pm 16.54 \%$ correct, Control $48.84 \pm 20.53 \%$ correct, $t(21)=0.205, p$ $=.839$ ) and in the acoustic condition (ADHD: $57.20 \pm$
12.88\% correct, Control: $65.38 \pm 12.32 \%$ correct, $t(21)=$ -1.527, $p=.142$ ).

There were neither group differences in antisaccade latency in the visual condition (ADHD: $493.36 \pm 196.43$ ms, Control: $441.00 \pm 146.65 \mathrm{~ms}, Z(21)=0.504$, $p=.614$ ), nor in the acoustic condition (Antisaccades: ADHD: $696.25 \pm 258.34 \mathrm{~ms}$, Control: $639.94 \pm 226.71$ ms, $t(21)=0.551, p=.588)$.

\section{Pre-saccadic brain activity}

A significant group difference was identified for the acoustic antisaccade condition between 228 and $140 \mathrm{~ms}$ before antisaccade onset $(t(21)=74.707, p<.05)$ in the MFC source and at 112-0 ms before antisaccade onset $(t(21)=76.294, p<.05)$ in the TAC left source. Children with ADHD showed higher source activity than control children (MFC: ADHD: $67.09 \pm 40.16 \mathrm{nAm}$, Control. $34.59 \pm 13.49$ nAm, see Figure 3; TAC left: ADHD: 61.83 $\pm 31.80 \mathrm{nAm}$, Control 31.34 $\pm 20.18 \mathrm{nAm}$, see Figure 4).

In contrast, no significant group differences were revealed in the visual antisaccade condition in either of these sources or any other source.

\section{Discussion}

Aim of this study was to investigate differences in response inhibition and corresponding brain activity between children with and without ADHD. Response inhibition was measured in an antisaccade task where saccades were either elicited by acoustic or visual cues.

The main finding of the study was that children with and without ADHD differed in brain activity when saccades were elicited by acoustic cues. Children with ADHD had a higher source activity than control children in the MFC source between -228 and $-140 \mathrm{~ms}$ and in the left-hemispheric TAC source between -112 and 0 ms before saccade onset. These time windows overlap with the critical period for response inhibition in visual antisaccade tasks [29,30,47].

\section{Behavioural data}

No group differences regarding the correctness of saccade execution were found in the present study. Other

Table 1 Results hearing levels

\begin{tabular}{|c|c|c|c|c|c|c|c|c|c|}
\hline \multirow[b]{2}{*}{ Side tested } & \multirow[b]{2}{*}{ Test } & \multirow[b]{2}{*}{ Frequency $(\mathrm{Hz})$} & \multicolumn{2}{|c|}{ ADHD $(n=9)$} & \multicolumn{2}{|c|}{ Control $(n=14)$} & \multirow[b]{2}{*}{ t/Z- value } & \multirow[b]{2}{*}{ df } & \multirow[b]{2}{*}{$\mathrm{p}$} \\
\hline & & & Mean & SD & Mean & SD & & & \\
\hline & t-test & 500 & 4.67 & 5.05 & 3.50 & 4.15 & 0.605 & 21 & 0.552 \\
\hline \multirow[t]{4}{*}{ Right } & t-test & 1000 & 1.56 & 4.98 & 0.21 & 3.93 & 0.721 & 21 & 0.479 \\
\hline & t-test & 2000 & -0.89 & 4.83 & -0.79 & 4.92 & -0.049 & 21 & 0.961 \\
\hline & t-test & 4000 & 0.33 & 5.36 & -0.93 & 6.81 & 0.469 & 21 & 0.644 \\
\hline & t-test & 500 & 3.00 & 7.45 & 3.36 & 5.42 & -0.133 & 21 & 0.895 \\
\hline \multirow[t]{3}{*}{ Left } & MWU & 1000 & -1.33 & 8.02 & -0.86 & 6.77 & -0.031 & 21 & 0.975 \\
\hline & MWU & 2000 & -2.67 & 5.55 & 0.07 & 8.40 & -0.661 & 21 & 0.508 \\
\hline & MWU & 4000 & -2.00 & 6.08 & -0.43 & 9.49 & -0.504 & 21 & 0.614 \\
\hline
\end{tabular}


Table 2 Results parental ratings of ADHD/APD symptoms

\begin{tabular}{|c|c|c|c|c|c|c|c|c|c|c|c|c|}
\hline \multirow[b]{2}{*}{ Symptoms } & \multirow[b]{2}{*}{ Sub-scales } & \multirow[b]{2}{*}{ Test } & \multicolumn{3}{|c|}{ ADHD } & \multicolumn{3}{|c|}{ Control } & \multirow[b]{2}{*}{ t/Z-value } & \multirow[b]{2}{*}{ df } & \multirow{2}{*}{\multicolumn{2}{|c|}{$\mathrm{p}$}} \\
\hline & & & $\mathrm{n}$ & Mean & SD & $\mathrm{n}$ & Mean & SD & & & & \\
\hline \multirow[t]{4}{*}{ ADHD } & Inattention & MWU & 9 & 34.00 & 7.38 & 14 & 14.71 & 2.40 & 3.874 & 21 & 0.000 & $* * *$ \\
\hline & Hyperactivity/Impulsivity & MWU & 9 & 3.09 & 0.67 & 14 & 1.34 & 0.22 & 3.969 & 21 & 0.000 & $* * *$ \\
\hline & Speech Perception & t-test & 9 & 1.89 & 0.73 & 13 & 1.29 & 0.25 & 2.767 & 20 & 0.012 & $*$ \\
\hline & Auditory Discrimination & MWU & 9 & 1.38 & 0.72 & 14 & 1.14 & 0.23 & 0.787 & 21 & 0.380 & \\
\hline \multirow[t]{4}{*}{ APD } & Sound Localisation & MWU & 9 & 1.27 & 0.53 & 14 & 1.01 & 0.05 & 1.134 & 21 & 0.086 & \\
\hline & Hearing in background noise & MWU & 9 & 1.63 & 0.78 & 14 & 1.48 & 0.41 & 0.157 & 21 & 0.874 & \\
\hline & Auditory Memory & MWU & 9 & 1.81 & 0.65 & 14 & 1.30 & 0.42 & 2.331 & 21 & 0.019 & $*$ \\
\hline & Auditory Hypersensitivity & t-test & 9 & 2.77 & 0.64 & 13 & 2.48 & 0.62 & 1.058 & 20 & 0.303 & \\
\hline
\end{tabular}

studies on antisaccades using only visual cues revealed an elevated number of direction errors in children with ADHD [4], indicating that these children are less able than control children to inhibit inappropriate responses. However, there are also studies in line with the present findings [48-50] without group differences. The random design of experimental presentation in the present study was chosen to increase task difficulty in order to differentiate between the groups. However, it might have been the case that the task was equally more difficult for both, control children and children with ADHD, as supplementary task switching between pro- and antisaccades is required [12,51], thus concealing group effects.

Another explanation for the negative finding of behavioural group differences might be related to the age range of the children in the present study. Rothlind and colleagues [50] investigated a group of children with a similar age range. The mean age of their ADHD group was $10.5 \pm 2.4$ years (range: $6.9-13.9$ years), mean age of the control group was $9.9 \pm 2.8$ years (range: $6.8-14.4$ years). As in the present study, Rothlind and colleagues did not find any group differences in saccadic errors. Other studies have used groups of children with a smaller age-range and were able to find more errors in children with ADHD [5,6,8,10-12]. A reason might be that boys younger than 11 years have difficulty with oculomotor inhibition in general $[52,53]$. However, a study with younger children has also found differences between children with and without ADHD [10] and thus questions the assumption of a general oculomotor inhibition deficit in younger children. Finally the subtype of ADHD might be an influencing factor on performance in saccade tasks.

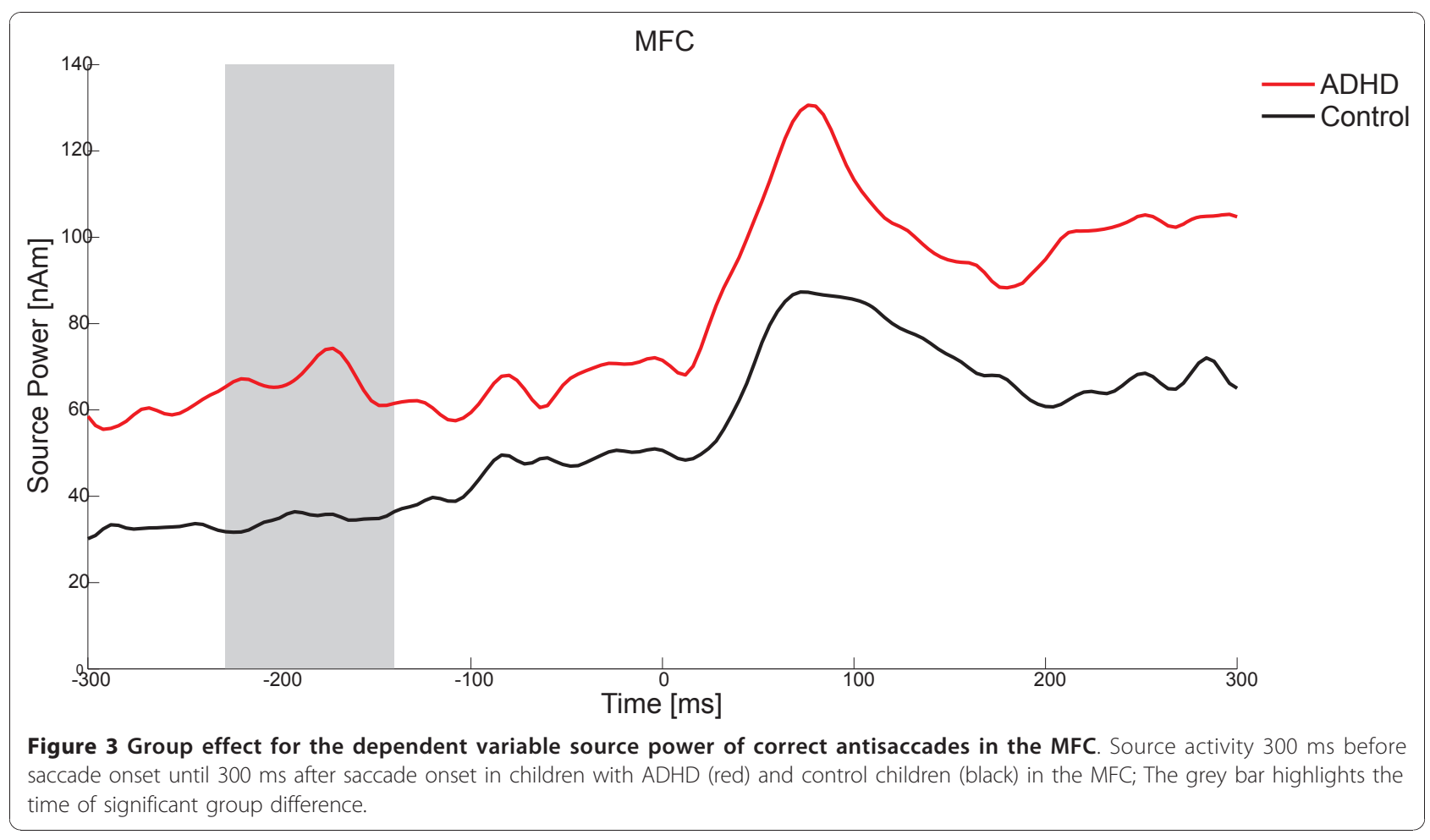




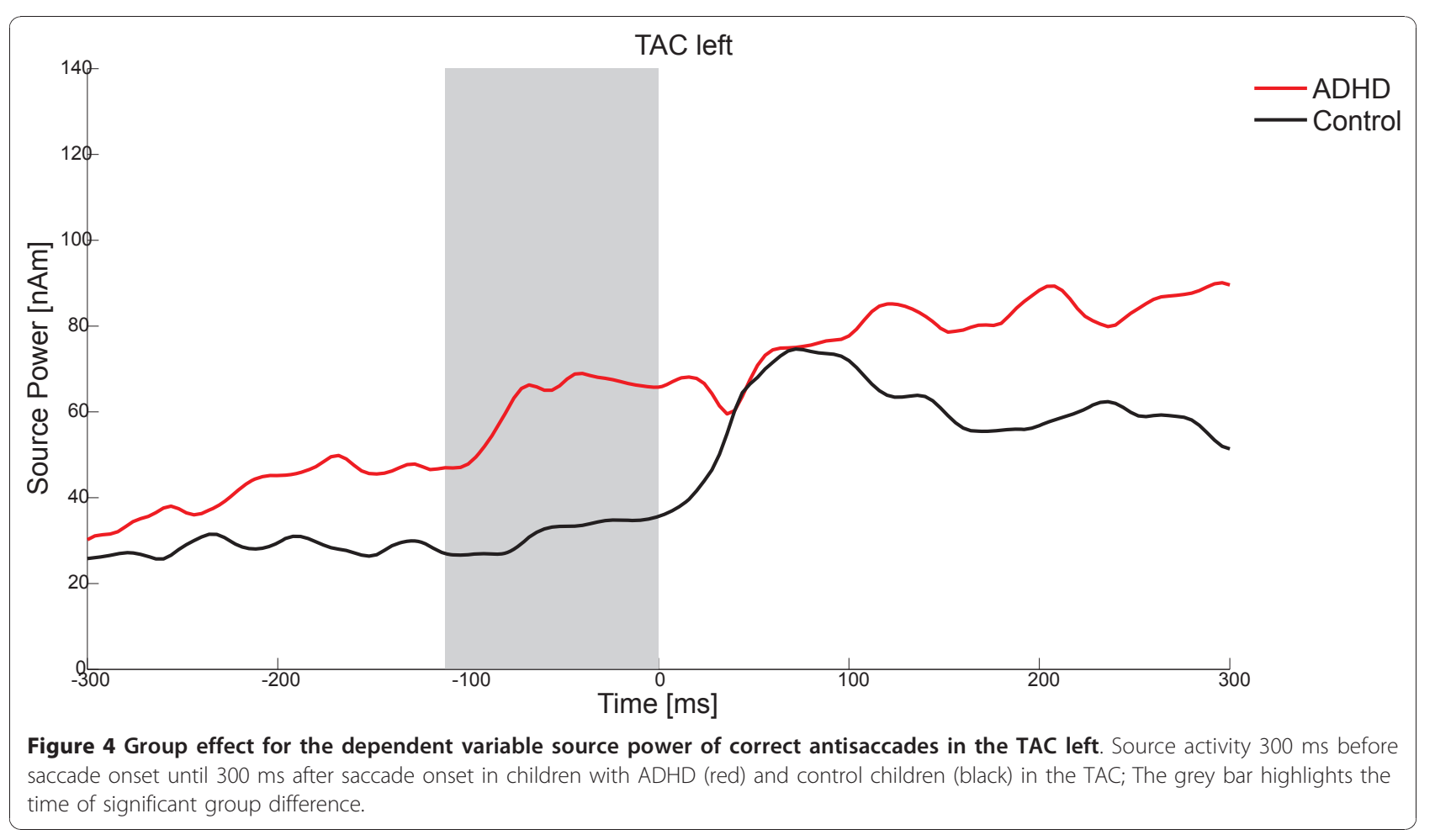

Children with ADHD combined type made more antisaccade errors than control children, while no group differences were found between children with ADHD inattentive type and control children [12]. In the present study eight of nine children with ADHD had the diagnose ADHD combined type. Thus, ADHD subtype is not likely to have influenced the response pattern in the present study.

As for saccadic correctness, no group differences were found for SRTs in the present study. The latency of correct antisaccades was not investigated in all saccade studies and results are inconsistent. Some studies found slower antisaccade latencies in children with ADHD compared with control children [5-10]. Other studies found no group differences in antisaccades latencies $[12,50]$, which is in line with the present result.

Thus, it is still unclear why no group differences were found in the rate of correct saccades and its latencies. The small sample size - which resulted from the fact that only ADHD children off medication were included - and the relatively big age range seem to be the most likely explanation. However, an absence of behavioural differences reduces ambiguities in the interpretation of any effects in brain measures.

\section{Pre-saccadic brain activity}

Indeed, source activation differed between groups in the acoustic condition. Children with ADHD had higher activation of the MFC and the left-hemispheric TAC compared to control children during time-windows likely to reflect response inhibition. MFC includes parts of the dorsal ACC, which is connected with the prefrontal cortex and parietal cortex as well as the motor system and the frontal eye fields [54-56]. It is crucially involved in the executive control of attention. The ACC plays an important role in visual antisaccade performance [24,31-33] and ACC activity seems to be altered in patients with ADHD [57-60]. In the present study, children with ADHD had higher activity in the MFC source than control children preceding an auditory antisaccade. Still, behavioural performance, i.e. the percentage of correctly executed saccades did not differ between the groups. It thus appears that children with ADHD needed more activation of the MFC to reach the same level of response inhibition as control children. The present results were found only when saccades were elicited by acoustic cues. Still, a comparable pattern of brain activation results was found in studies investigating response inhibition in a visual go/nogo task design $[35,61,62]$. The present results are also in line with a meta - analysis [35], which concluded that there are two brain areas, in which ADHD patients have significantly more activation than controls: the medial frontal gyrus and the right secondary somatosensory area.

Activation of the left TAC source was higher in children with ADHD than in control children preceding antisaccades. Results from other experiments regarding 
temporal lobe activity during cognitive tasks are inconsistent. There seems to be some evidence of dysfunction and also of compensatory use of the temporal lobes in ADHD [63]. However, the current finding is in line with a go/nogo study in which children with ADHD showed more activation than the control children in the middle/ inferior/superior temporal gyrus [64]. This might be also related to structural abnormalities in children with ADHD [36]. Castellanos and colleagues [65,66] showed that children with ADHD have a reduced volume of frontal and temporal gray matter, caudate, and cerebellum. These volume reductions were related with measures of symptom severity in an ADHD sample [65,67]. Another study detected reduced brain volumes in the lateral anterior and midtemporal cortices bilaterally [68]. Lateral temporal and parietal regions are part of the cross-modal association cortex, which also includes the DLPFC. This system integrates information from lower order sensory systems into higher order rules and functions. It is assumed that these regions together - beside their anatomical interconnection - form a broadly distributed action-attention system that supports the maintenance of attentional focus and successful inhibition [68-70]. It might be speculated that because of the smaller volume of the temporal cortex, children with ADHD showed more reflexive reaction to acoustic cues. Because of that, more frontal activation might have been needed as well in order to control behavioural output.

Finally, group differences in brain activation during acoustically elicited antisaccades are in line with auditory deficits (in Speech Perception and Auditory Memory) as detected in the APD questionnaire in the present study. The results are also in line with a suggested symptom overlap of children with ADHD and children with APD [71-74]. APD is characterised by disturbed hearing despite a normally functioning periphery. Typical symptoms are poor recognition, discrimination, separation, grouping, localisation, ordering of nonspeech sounds and difficulties with acoustic tasks when competing acoustic signals are present $[75,76]$. Both, children with APD and children with ADHD, have difficulty paying attention and remembering information presented orally, are easily distracted, have difficulty following complex auditory directions or commands, and show low academic performance. The present results also demonstrate that acoustic processing should be a focus of interest in ADHD research. Knowing more about alterations of the auditory systems and according consequences might enable better differentiation of the ADHD/APD diagnosis.

In summary, both structures - MFC and the left-hemispheric TAC - are part of functional brain areas involved in attention and response inhibition, and seem to be functionally or structurally altered in children with ADHD.
Against expectations, no differences in brain activity were found in the visual antisaccade condition. There might be many contributing factors such as sample size, task design, and age range, as mentioned above. It is not possible to directly compare the present results to previous findings, as no other studies have investigated brain activation during antisaccades in children with ADHD. However, it should be noted that there are inconsistent findings in imaging studies of other visual inhibition tasks. Some studies reported that ADHD children exhibit a smaller P3 amplitude than control children [60,77-79], and showed lower activation of inferior prefrontal cortex and other brain regions $[35,80,81]$. Other authors found increased activation in prefrontal brain regions $[61,62]$ and in the medial frontal gyrus respectively [35]. Again, it is difficult to compare studies using different inhibition tasks. More research with bigger sample sizes and a smaller age range are needed to answer to the question if there are differences in brain activity between children with and without ADHD during visually cued antisaccades.

\section{Conclusion}

In sum, the present study for the first time provides insight in the cortical network underlying the production of antisaccades elicited by acoustic stimuli in children with and without ADHD. While no group differences were found when visual cues were used, results showed that functioning of the Anterior Temporal Lobe and Medio-Frontal Cortex is altered in children with ADHD when acoustic cues are used to trigger antisaccades. The present results support the hypothesis that cortical structures underlying response inhibition are more active in children with ADHD to achieve the same behavioural output as children without ADHD, possibly as a compensatory mechanism.

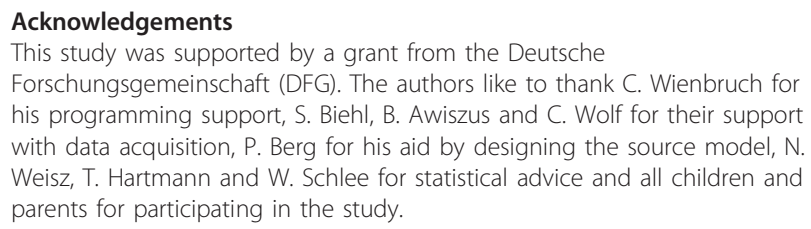

Authors' contributions

JG carried out the subject selection, data acquisition, data processing, statistics and the preparation of the manuscript. Substantial contribution to study design, data analysis and the maniscript was made by JK. BR supervised the study and offered advice on data analysis and manuscript preparation. The study was designed by IPJ. Additionally she carried out statistics and corrected the manuscript.

All authors read and approved the final manuscript.

\section{Competing interests}

The authors declare that they have no competing interests.

Received: 15 September 2010 Accepted: 12 January 2011 Published: 12 January 2011 


\section{References}

1. Willcutt EG, Doyle AE, Nigg JT, Faraone SV, Pennington BF: Validity of the executive function theory of attention-deficit/hyperactivity disorder: a meta-analytic review. Biol Psychiatry 2005, 57(11):1336-1346.

2. Barkley RA: Attention-Deficit/Hyperactivity Disorder. In Attention-Deficit Disoder: A Handbook For Diagnosis And Treatment. Volume 3. New York: The Guildford Press; 1991:75-143.

3. Everling S, Fischer B: The antisaccade: a review of basic research and clinical studies. Neuropsychologia 1998, 36(9):885-899.

4. Rommelse NN, Van der Stigchel S, Sergeant JA: A review on eye movement studies in childhood and adolescent psychiatry. Brain Cogn 2008, 68(3):391-414.

5. Karatekin C: Improving antisaccade performance in adolescents with attention-deficit/hyperactivity disorder (ADHD). Exp Brain Res 2006, 174(2):324-341.

6. Klein C, Raschke A, Brandenbusch A: Development of pro- and antisaccades in children with attention-deficit hyperactivity disorder (ADHD) and healthy controls. Psychophysiology 2003, 40(1):17-28.

7. Mostofsky SH, Lasker AG, Singer HS, Denckla MB, Zee DS: Oculomotor abnormalities in boys with tourette syndrome with and without ADHD. J Am Acad Child Adolesc Psychiatry 2001, 40(12):1464-1472.

8. Munoz DP, Armstrong IT, Hampton KA, Moore KD: Altered control of visual fixation and saccadic eye movements in attention-deficit hyperactivity disorder. J Neurophysiol 2003, 90(1):503-514.

9. Mostofsky SH, Lasker AG, Cutting LE, Denckla MB, Zee DS: Oculomotor abnormalities in attention deficit hyperactivity disorder: a preliminary study. Neurology 2001, 57(3):423-430.

10. Goto Y, Hatakeyama K, Kitama T, Sato Y, Kanemura H, Aoyagi K, Sugita K, Aihara M: Saccade eye movements as a quantitative measure of frontostriatal network in children with ADHD. Brain Dev 2010.

11. Mahone EM, Mostofsky SH, Lasker AG, Zee D, Denckla MB: Oculomotor anomalies in attention-deficit/hyperactivity disorder: evidence for deficits in response preparation and inhibition. J Am Acad Child AdolesC Psychiatry 2009, 48(7):749-756.

12. O'Driscoll GA, Depatie L, Holahan AL, Savion-Lemieux T, Barr RG, Jolicoeur C, Douglas VI: Executive functions and methylphenidate response in subtypes of attention-deficit/hyperactivity disorder. Biol Psychiatry 2005, 57(11):1452-1460.

13. Loe IM, Feldman HM, Yasui E, Luna B: Oculomotor performance identifies underlying cognitive deficits in attention-deficit/hyperactivity disorder. J Am Acad Child Adolesc Psychiatry 2009, 48(4):431-440.

14. Muir D, Field J: Newborn infants orient to sounds. Child Dev 1979, 50(2):431-436

15. Sutcliffe PA, Bishop DV, Houghton S, Taylor M: Effect of attentional state on frequency discrimination: a comparison of children with ADHD on and off medication. J Speech Lang Hear Res 2006, 49(5):1072-1084.

16. Breier JI, Fletcher JM, Foorman BR, Klaas P, Gray LC: Auditory temporal processing in children with specific reading disability with and without attention deficit/hyperactivity disorder. J Speech Lang Hear Res 2003, 46(1):31-42.

17. Tillery KL, Katz J, Keller WD: Effects of methylphenidate (Ritalin) on auditory performance in children with attention and auditory processing disorders. J Speech Lang Hear Res 2000, 43(4):893-901.

18. Munoz DP, Everling S: Look away: the anti-saccade task and the voluntary control of eye movement. Nat Rev Neurosci 2004, 5(3):218-228.

19. Pierrot-Deseilligny C, Milea D, Muri RM: Eye movement control by the cerebral cortex. Curr Opin Neurol 2004, 17(1):17-25.

20. Pierrot-Deseilligny $C$, Muri RM, Nyffeler T, Milea D: The role of the human dorsolateral prefrontal cortex in ocular motor behavior. Ann N Y Acad Sci 2005, 1039:239-251.

21. Ploner CJ, Gaymard BM, Rivaud-Pechoux S, Pierrot-Deseilligny C: The prefrontal substrate of reflexive saccade inhibition in humans. Biol Psychiatry 2005, 57(10):1159-1165.

22. Pierrot-Deseilligny C, Muri RM, Ploner CJ, Gaymard B, Demeret S, RivaudPechoux S: Decisional role of the dorsolateral prefrontal cortex in ocular motor behaviour. Brain 2003, 126(Pt 6):1460-1473.

23. Pierrot-Deseilligny C, Rivaud S, Gaymard B, Agid Y: Cortical control of reflexive visually-guided saccades. Brain 1991, 114(Pt 3):1473-1485.

24. Ford KA, Goltz HC, Brown MR, Everling S: Neural processes associated with antisaccade task performance investigated with event-related FMRI. $J$ Neurophysiol 2005, 94(1):429-440.
25. Connolly JD, Goodale MA, Menon RS, Munoz DP: Human fMRI evidence for the neural correlates of preparatory set. Nat Neurosci 2002 5(12):1345-1352

26. McDowell JE, Dyckman KA, Austin BP, Clementz BA: Neurophysiology and neuroanatomy of reflexive and volitional saccades: evidence from studies of humans. Brain Cogn 2008, 68(3):255-270.

27. Clementz BA, Gao Y, McDowell JE, Moratti S, Keedy SK, Sweeney JA: Topdown control of visual sensory processing during an ocular motor response inhibition task. Psychophysiology 2010

28. Fitzgerald KD, Zbrozek CD, Welsh RC, Britton JC, Liberzon I, Taylor SF: Pilot study of response inhibition and error processing in the posterior medial prefrontal cortex in healthy youth. J Child Psychol Psychiatry 2008, 49(9):986-994.

29. McDowell JE, Kissler JM, Berg P, Dyckman KA, Gao Y, Rockstroh B, Clementz BA: Electroencephalography/magnetoencephalography study of cortical activities preceding prosaccades and antisaccades. Neuroreport 2005, 16(7):663-668.

30. Clementz BA, McDowell JE, Stewart SE: Timing and magnitude of frontal activity differentiates refixation and anti-saccade performance. Neuroreport 2001, 12(9):1863-1868.

31. Brown MR, Goltz HC, Vilis T, Ford KA, Everling S: Inhibition and generation of saccades: rapid event-related $\mathrm{fMRI}$ of prosaccades, antisaccades, and nogo trials. Neuroimage 2006, 33(2):644-659.

32. Gaymard B, Ploner CJ, Rivaud S, Vermersch Al, Pierrot-Deseilligny C: Cortical control of saccades. Exp Brain Res 1998, 123(1-2):159-163.

33. Polli FE, Barton JJ, Cain MS, Thakkar KN, Rauch SL, Manoach DS: Rostral and dorsal anterior cingulate cortex make dissociable contributions during antisaccade error commission. Proc Natl Acad Sci USA 2005, 102(43):15700-15705

34. Bush G, Valera EM, Seidman L: Functional neuroimaging of attentiondeficit/hyperactivity disorder: a review and suggested future directions. Biol Psychiatry 2005, 57(11):1273-1284

35. Dickstein SG, Bannon K, Castellanos FX, Milham MP: The neural correlates of attention deficit hyperactivity disorder: an ALE meta-analysis. J Child Psychol Psychiatry 2006, 47(10):1051-1062.

36. Seidman $L$, Valera EM, Makris N: Structural brain imaging of attentiondeficit/hyperactivity disorder. Biol Psychiatry 2005, 57(11):1263-1272.

37. WMA: World Medical Association Declaration of Helsinki: ethical principles for medical research involving human subjects. J Int Bioethique 2004, 15(1):124-129.

38. Lauth GW, Schlottke PF: Training mit aufmerksamkeitsgestörten Kindern. Diagnostik und Therapie. 5 edition. Weinheim: Belz, Psychologie Verlags Union; 2002.

39. Anamnesebogen zur Erfassung Auditiver Verarbeitungs- und Wahrnehmungsstörungen (AVWS). [http://www.dgpp.de/Profi/index_Profi. htm].

40. Oldfield RC: The assessment and analysis of handedness: the Edinburgh inventory. Neuropsychologia 1971, 9(1):97-113.

41. Raven JC, Raven J, Court JH: Coloured Progressive Matrices Frankfurt: Swets \& Zeitlinger B.V., Swets Test Services; 2002.

42. Berg P, Scherg M: A multiple source approach to the correction of eye artifacts. Electroencephalogr Clin Neurophysiol 1994, 90(3):229-241.

43. Lins OG, Picton TW, Berg P, Scherg M: Ocular artifacts in EEG and eventrelated potentials. I: Scalp topography. Brain Topogr 1993, 6(1):51-63.

44. Klein C: Developmental functions for saccadic eye movement parameters derived from pro- and antisaccade tasks. Exp Brain Res 2001, 139(1):1-17.

45. Maris E, Oostenveld R: Nonparametric statistical testing of EEG- and MEGdata. J Neurosci Methods 2007, 164(1):177-190.

46. ASHA: Guidelines for Audiologic Screening [Guidelines]. American SpeechLanguage-Hearing Association 1997.

47. Clementz BA, Brahmbhatt SB, McDowell JE, Brown R, Sweeney JA: When does the brain inform the eyes whether and where to move? An EEG study in humans. Cereb Cortex 2007, 17(11):2634-2643.

48. Aman CJ, Roberts RJ Jr, Pennington BF: A neuropsychological examination of the underlying deficit in attention deficit hyperactivity disorder: frontal lobe versus right parietal lobe theories. Dev Psychol 1998, 34(5):956-969.

49. Hanisch C, Radach R, Holtkamp K, Herpertz-Dahlmann B, Konrad K: Oculomotor inhibition in children with and without attention-deficit hyperactivity disorder (ADHD). J Neural Transm 2006, 113(5):671-684. 
50. Rothlind JC, Posner MI, Schaughency EA: Lateralized control of eye movements in attention deficit hyperactivity disorder. Journal of Cognitive Neuroscience 1991, 3(4):377-381.

51. Irving EL, Tajik-Parvinchi DJ, Lillakas L, Gonzalez EG, Steinbach MJ: Mixed pro and antisaccade performance in children and adults. Brain Res 2009 1255:67-74.

52. Klein C, Foerster F: Development of prosaccade and antisaccade task performance in participants aged 6 to 26 years. Psychophysiology 2001, 38(2):179-189.

53. Fischer B, Biscaldi M, Gezeck S: On the development of voluntary and reflexive components in human saccade generation. Brain Res 1997, 754(1-2):285-297.

54. Brown MR, Vilis T, Everling S: Frontoparietal activation with preparation for antisaccades. J Neurophysiol 2007, 98(3):1751-1762.

55. Ding J, Powell $D$, Jiang Y: Dissociable frontal controls during visible and memory-guided eye-tracking of moving targets. Hum Brain Mapp 2009, 30(11):3541-3552.

56. Wang Y, Matsuzaka Y, Shima K, Tanji J: Cingulate cortical cells projecting to monkey frontal eye field and primary motor cortex. Neuroreport 2004 15(10):1559-1563.

57. Bush G, Frazier JA, Rauch SL, Seidman LJ, Whalen PJ, Jenike MA, Rosen BR, Biederman J: Anterior cingulate cortex dysfunction in attention-deficit/ hyperactivity disorder revealed by fMRI and the Counting Stroop. Biol Psychiatry 1999, 45(12):1542-1552

58. Colla M, Ende G, Alm B, Deuschle M, Heuser I, Kronenberg G: Cognitive MR spectroscopy of anterior cingulate cortex in ADHD: elevated choline signal correlates with slowed hit reaction times. J Psychiatr Res 2008, 42(7):587-595.

59. Fallgatter AJ, Ehlis AC, Seifert J, Strik WK, Scheuerpflug P, Zillessen KE, Herrmann MJ, Warnke A: Altered response control and anterior cingulate function in attention-deficit/hyperactivity disorder boys. Clin Neurophysiol 2004, 115(4):973-981

60. Paul-Jordanov I, Bechtold M, Gawrilow C: Methylphenidate and if-then plans are comparable in modulating the P300 and increasing response inhibition in children with ADHD. ADHD Attention Deficit and Hyperactivity Disorders 2010

61. Durston S, Tottenham NT, Thomas KM, Davidson MC, Eigsti IM, Yang Y, Ulug AM, Casey BJ: Differential patterns of striatal activation in young children with and without ADHD. Biol Psychiatry 2003, 53(10):871-878.

62. Vaidya CJ, Austin G, Kirkorian G, Ridlehuber HW, Desmond JE, Glover GH, Gabrieli JD: Selective effects of methylphenidate in attention deficit hyperactivity disorder: a functional magnetic resonance study. Proc Nat/ Acad Sci USA 1998, 95(24):14494-14499.

63. Cherkasova MV, Hechtman L: Neuroimaging in attention-deficit hyperactivity disorder: beyond the frontostriatal circuitry. Can J Psychiatry 2009, 54(10):651-664

64. Tamm L, Menon V, Ringel J, Reiss AL: Event-related FMRI evidence of frontotemporal involvement in aberrant response inhibition and task switching in attention-deficit/hyperactivity disorder. J Am Acad Child Adolesc Psychiatry 2004, 43(11):1430-1440.

65. Castellanos FX, Lee PP, Sharp W, Jeffries NO, Greenstein DK, Clasen LS Blumenthal JD, James RS, Ebens CL, Walter JM, et al: Developmental trajectories of brain volume abnormalities in children and adolescents with attention-deficit/hyperactivity disorder. JAMA 2002, 288(14):1740-1748

66. Castellanos FX, Giedd JN, Berquin PC, Walter JM, Sharp W, Tran T, Vaituzis AC, Blumenthal JD, Nelson J, Bastain TM, et al: Quantitative brain magnetic resonance imaging in girls with attention-deficit/hyperactivity disorder. Arch Gen Psychiatry 2001, 58(3):289-295.

67. Casey BJ, Castellanos FX, Giedd JN, Marsh WL, Hamburger SD, Schubert AB, Vauss YC, Vaituzis AC, Dickstein DP, Sarfatti SE, et al: Implication of right frontostriatal circuitry in response inhibition and attention-deficit/ hyperactivity disorder. J Am Acad Child Adolesc Psychiatry 1997, 36(3):374-383

68. Sowell ER, Thompson PM, Welcome SE, Henkenius AL, Toga AW, Peterson BS: Cortical abnormalities in children and adolescents with attention-deficit hyperactivity disorder. Lancet 2003, 362(9397):1699-1707.

69. Mesulam MM: From sensation to cognition. Brain 1998, 121(pt 6):1013-1052.

70. Peterson BS, Skudlarski P, Gatenby JC, Zhang H, Anderson AW, Gore JC: An fMRI study of Stroop word-color interference: evidence for cingulate subregions subserving multiple distributed attentional systems. Biol Psychiatry 1999, 45(10):1237-1258.

71. Cacace AT, McFarland DJ: Delineating Auditory Processing Disorder (APD) and Attention Deficit Hyperactivity Disorder (ADHD): A Conceptual, Theoretical, and Practical Framework. In An introduction to auditory processing disorders in children. Edited by: Parthasarathy TK. New Jersey: Lawrence Erlbaum Associates, Inc; 2006:39-61.

72. Dawes P, Bishop D: Auditory processing disorder in relation to developmental disorders of language, communication and attention: a review and critique. Int J Lang Commun Disord 2009, 44(4):440-465.

73. Witton C: Childhood auditory processing disorder as a developmental disorder: the case for a multi-professional approach to diagnosis and management. Int J Audiol 2010, 49(2):83-87.

74. Keller WD, Tillery KL: Reliable Differential Diagnosis and Effective Management of Auditory Processing and Attention Deficit Hyperactivity Disorders. Semin Hear 2002, 23(4):337-348.

75. ASHA: (Central) Auditory Processing Disorders [Technical Report]. American Speech-Language-Hearing Association 2005.

76. BSA: Auditory Processing Disoder. British Society of Audiology Steering Group British Society of Audiology Steering Group; 2007.

77. Paul I, Gawrilow C, Zech F, Gollwitzer P, Rockstroh B, Odenthal G, Kratzer W, Wienbruch C: If-then planning modulates the P300 in children with attention deficit hyperactivity disorder. Neuroreport 2007, 18(7):653-657.

78. Kemner C, Verbaten MN, Koelega HS, Buitelaar JK, van der Gaag RJ, Camfferman G, van Engeland H: Event-related brain potentials in children with attention-deficit and hyperactivity disorder: effects of stimulus deviancy and task relevance in the visual and auditory modality. Biol Psychiatry 1996, 40(6):522-534.

79. Liotti M, Pliszka SR, Perez R, Kothmann D, Woldorff MG: Abnormal brain activity related to performance monitoring and error detection in children with ADHD. Cortex 2005, 41(3):377-388.

80. Rubia K, Overmeyer S, Taylor E, Brammer M, Williams SC, Simmons A, Bullmore ET: Hypofrontality in attention deficit hyperactivity disorder during higher-order motor control: a study with functional MRI. Am J Psychiatry 1999, 156(6):891-896.

81. Rubia K, Smith AB, Brammer MJ, Toone B, Taylor E: Abnormal brain activation during inhibition and error detection in medication-naive adolescents with ADHD. Am J Psychiatry 2005, 162(6):1067-1075.

\section{Pre-publication history}

The pre-publication history for this paper can be accessed here: http://www.biomedcentral.com/1471-244X/11/7/prepub

doi:10.1186/1471-244X-11-7

Cite this article as: Goepel et al:: Medio-Frontal and Anterior Temporal abnormalities in children with attention deficit hyperactivity disorder (ADHD) during an acoustic antisaccade task as revealed by electro-cortical source reconstruction. BMC Psychiatry 2011 11:7.

\section{Submit your next manuscript to BioMed Central and take full advantage of:}

- Convenient online submission

- Thorough peer review

- No space constraints or color figure charges

- Immediate publication on acceptance

- Inclusion in PubMed, CAS, Scopus and Google Scholar

- Research which is freely available for redistribution

Submit your manuscript at www.biomedcentral.com/submit
C Biomed Central 